\title{
VOLKSWAGEN DE MÉXICO: REESTRUCTURACIÓN, FLEXIBILIDAD Y CONFLICTOS ${ }^{1}$
}

\section{Volkswagen of Mexico: restructuring, flexibility and conflicts}

Mario Millones Espinosa²

Universidad de Artes y Ciencias Sociales (U-ARCIS), Santiago, Chile.

Recibido: 26 de mayo de 2011. Aprobado: 28 de noviembre de 2011.

\section{RESUMEN}

El objetivo de este trabajo es estudiar el proceso de reestructuración productiva y flexibilidad laboral en la empresa automotriz Volkswagen de México. El año 1992 se firma un nuevo Contrato Colectivo de Trabajadores, el cual crea un complejo encadenamiento productivo utilizando la subcontratación en toda la producción del automóvil, dejando solo el ensamblaje final a Volkswagen. Luego de estos cambios, Volkswagen se posicionó como una de las empresas líderes en el mercado mundial del automóvil. El nuevo proceso productivo incluirá una alta coordinación y competencia inter e intrafirmas, pero también fuertes sistemas de control, vigilancia y castigo a trabajadores y proveedoras que no cumplan con los requerimientos de Volkswagen. En esta atracción de más proveedores se producirán alianzas estratégicas entre firmas trasnacionales, dejando a empresas locales solo como proveedoras de baja tecnología a través de contratos de tiempo determinado. La fuerte diferenciación tecnológica dentro del encadenamiento productivo será la misma que diferenciará las condiciones de trabajo entre empresas locales y extranjeras, sin embargo, eso está cambiando. La flexibilidad laboral aplicada en el Contrato Colectivo por Volkswagen señala una creciente precarización del trabajo, tanto en esta empresa como en toda la industria automotriz.

1 Este artículo forma parte de la tesis de Magíster en Sociología: "Los límites del Trabajo Decente: flexibilización y conflictos en Volkswagen de México", de la Escuela Latinoamericana de Estudios de Postgrado y Políticas Públicas (ELAP), Universidad de Artes y Ciencias Sociales (U-ARCIS). Financiada por programa FIC - 2008, Universidad Arturo Prat del Estado de Chile (UNAP), Iquique.

2 Licenciado en Sociología por la Universidad Arturo Prat, Magíster en Sociología por la Escuela Latinoamericana de Estudios de Postgrado y Políticas Públicas (ELAP), Universidad de Artes y Ciencias Sociales (U-ARCIS). Correo electrónico: mario.millones.espinosa@gmail.com 
PALABRAS CLAVE: Volkswagen, flexibilidad, restructuración productiva.

\begin{abstract}
The objective of this paper is study the process of productive restructuring and labor flexibility in the automaker Volkswagen of México. The year 1992 it signed a new Collective Bargaining Agreement, which creates a complex production chain using outsourcing in all production of a car, leaving only the final assembly at Volkswagen. After these changes, Volkswagen ranked as one of the leading companies in the global automotive market. This new productive process will include a high coordination and inter-and intra firm competition, but also strong control system, surveillance and punishment of farm worker and the same suppliers that do not meet the requirements of Volkswagen. In this attracting more suppliers produce strategic alliances between multinational firms, leaving local firm with low-tech as provider through contracts of time. The strong technological difference in the production chain will be the same working conditions differ between local and foreign companies, however, that is changing. The labor flexibility as applied in the Collective Bargaining Agreement for Volkswagen says a growing the precariousness of work in this the company and all automotive industry.
\end{abstract}

KEYWORDS: Volkswagen, flexibility, production restructuring.

\title{
I. INTRODUCCIÓN
}

De manera general, existe en los procesos productivos una clara división entre concepción y ejecución (Novick 2003). Este ejercicio, que se pronunciara de manera substancial con el sistema taylorista, constituyó técnicas aún más racionales como el toyotismo, la producción flexible o el Justo a Tiempo ${ }^{3}$ (Just In Time/Kanban-JIT/K-). De manera conjunta, estas técnicas se fueron expandiendo territorialmente, normalizando e institucionalizando su quehacer hasta llegar a establecerse como modelo productivo preferencial.

Humphrey y Schmitz (1995 citado en García 2008) señala, sin embargo, que a pesar de ser un modelo hegemónico los procesos de fusión y adaptación de las técni-

3 El JIT/K fue una respuesta clave para mejorar puntos preocupantes del sistema capitalista mundial: por un lado, mostraba medios alternativos para cubrir fricciones en los circuitos del capital productivo (sobre todo cuando había sobreproducción) y, por el otro, dejó en claro que la reorganización laboral, como administrativa, era imprescindible y altamente provechosa cuando no se enfrentaban a los marcos regulatorios rígidos (Juárez 2002). 
cas flexibilizadoras, a diferencia del fordismo, no han sido estrictamente unilineales en América Latina. Novick (2003), a su vez, indica que el modelo productivo regional al presentarse idiosincrático determina, sin duda, la propia aplicación de dichas técnicas. En efecto, la industrialización tardía y no solo tardía, sino también específica de la región, habría agenciado y construido tanto un imaginario como un modo concreto de operar, distinto al presenciado en Europa u otras regiones, a pesar que, en su mayoría, fuesen las mismas empresas ${ }^{4}$ (Humphrey y Schmitz 1995 citado en García 2008).

Las empresas automotrices en América Latina, por ejemplo, se vieron entramadas en varios hechos particulares en el siglo XX que influyeron en su actuar contextual, a saber: precariedad infraestructural, bajo consumo poblacional (bajo nivel adquisitivo), sustitución de importaciones (ISI), proteccionismo estatal, políticas crediticias, organización obrera, etc. Ello terminó por cerrar el círculo productivo idiosincrático, como lo señala Novick (2003).

Ahora bien, Dombois (1990 citado en Vieyra 1999:3) agrega que los principales motivos que movieron el traslado de estas a América Latina (y, en un caso específico, a México) manifiestan cierta sincronía con aquellas características, pues fue la posibilidad de reducción de costos productivos, transporte (con miras al mercado estadounidense), ahorro de salarios y que, por cierto, podrían ser mercados plausibles de monopolizar; los que indujeron la Inversión Extranjera Directa en la región. Sin embargo, termina de dibujar este panorama el hecho que las mismas empresas que se instalaron habrían tenido, por cierto, un inicio diferente al vivenciado en sus respectivas casas matrices. En efecto, las empresas que invirtieron en la región lo hicieron en un comienzo solo en calidad de distribuidoras de productos, por consiguiente, fueron empresas mucho más pequeñas, con procesos internos menos complejos y menos competitivos. Este acontecer habría propiciado economías de escalas más reducidas, a su vez, dependientes de políticas exteriores y de la toma de decisión de sus casas matrices. ${ }^{5}$

De esta manera, la flexibilización creciente en América Latina parece seguir obedeciendo a las mismas características antes señaladas, anticipando que las condiciones

4 Por ejemplo, entre los años 1975 y 1980 los salarios pagados por las empresas automotrices extranjeras en México eran equivalentes a 3,2 y 3,6 menos que en las casas matrices por la misma actividad. Para 1984, esta diferencia alcanzó 7,4 veces y en la década del 90 se mantuvo entre 6,9 y 9,8 (Moreno 1994 citado en Sosa 2005:205).

5 En América Latina, en plena etapa ISI se dieron mercados protegidos de competencias externas, lo que permitió a empresas multinacionales disfrutar de constantes subsidios, incentivos, transferencia de recursos de parte del Estado por largos periodos (Katz 1989 citado en Novick 2003), entre otras regalías. Con el cambio de siglo, estas modifican su forma pero continúan, esta vez, a través de bajas o nulas imposiciones arancelarias para exportación e importación con los tratados económicos y políticos de libre comercio. 
laborales dependen más de decisiones político-económicas que se encuentran fuera del entorno inmediato al trabajo o, mejor dicho, en países y empresas lejanas que poco velan por el trabajador de México u otro país de la región. El presente artículo, en su intento de develar este proceso complejo, toma el caso de la industria automotriz Volkswagen de México (VWM), sobre todo a partir del año 1992, cuando comienza a flexibilizarse su estructura productiva. Para ello, el artículo está dividido en cinco partes: primero, se esboza la aplicación del modelo de producción flexible en la región; segundo, se entregan antecedentes de la industria automotriz mexicana con sus principales componentes: ensambladoras y autopartes; tercero, se desarrolla la estructura productiva de VWM, y cuarto, se exhiben los cambios producidos por el proceso de flexibilización en el Contrato Colectivo de Trabajadores de VWM de 1992, más algunos datos de actuales conflictos.

\section{INCURSIÓN DE LA PRODUCCIÓN FLEXIBLE EN AMÉRICA LATINA}

En América Latina, la producción flexible o toyotismo comienza su incursión de diferentes formas, no estando claro si realmente fue por periodos de baja inversión (Novick 2003) o de fuerte especulación financiera (Salerno 1992 citado en Novick 2003). El comienzo de la aplicación de la producción flexible trajo pequeños cambios tecnológicos, técnicas organizacionales puntuales, Just in Time solo con algunos proveedores o solo en algunas etapas del proceso. Por esta forma no lineal, la aplicación de este modelo en la región ha recibido variedad de nombres particulares, entre ellos, "jit taylorizado" (Humphrey 1990 citado en Novick 2003) o “jit a 2003 la criolla” (Roldán 1993 citado en Novick 2003). Tales motivos llevan a Coriat (1995 citado en Novick 2003) a establecer más bien la concepción de "vía japonesa" a cualquier intento de flexibilización en la búsqueda de productividad hacia lo interno por polivalencia y movilización de las fuerzas de trabajo.

A grandes rasgos, la productividad con este nuevo modelo gerencial deja de ser concebida como una adición mecánica: la producción pasa a ser resultante, más bien, de gobernabilidad y control sobre la empresa y su entorno. Primero, sobre el trabajador; luego sobre la sociedad civil. Así, la idea de gestión se trasladó a la organización al disciplinar, controlar y vigilar; y en la producción, a evitar excesos en cualquiera de sus partes y formas (Novick 2003). Dicho de otro modo, la gobernabilidad al interior de las empresas fue la clave para evitar excesos de producción, pasando desde el control de la máquina al control de los cuerpos en el tiempo laboral. 
Los ejemplos de estas aplicaciones son varios y las técnicas también: ha habido negociaciones colectivas, imposiciones arbitrarias de contratos o cláusulas, aplicación solo a algunos modelos o etapas de la producción, subsidios, chantajes a sindicatos o alianzas con los mismos, entre otras. Pries (1998) afirma, en este sentido, que la principal lección del éxito de las empresas japonesas a nivel mundial y que en América Latina bien se entendió fue, precisamente, que no son tantos los factores "duros" (como la tecnología), sino más bien los factores "blandos" (gobernabilidad) los que explicarían la superioridad competitiva. Con ello, entonces, el modelo flexible promueve su obligatoriedad sistémica y sistemática, pues supone mejores condiciones competitivas en el mercado mundial a costa de un mejor manejo de técnicas de control; hecho que se puede evidenciar en el caso de Volkwagen en la Industria Automotriz de México.

\section{ANTECEDENTES DE LA INDUSTRIA AUTOMOTRIZ EN MÉXICO}

A modo de síntesis, la evolución de esta industria ha seguido las siguientes etapas: a) nacimiento (1925-1960), b) período ISI (1962-1976), c) competencia internacional y promoción de exportaciones (1977-1989), d) apertura comercial (1990-1993), e) Tratado de Libre Comercio de América del Norte (1994-2000), y f) mayor competitividad (2001-presente) (Vicencio 2007:216 y siguientes). Por otro lado, Pries (1998) establece tres etapas respecto a las relaciones industriales: la primera (1925-1960) se caracterizaría por el establecimiento de relaciones de control oficialistas de la mano de obra; la segunda (1960-1980) se ve marcada por el surgimiento del nuevo sindicalismo, que se vio favorecido tanto por un mayor protagonismo del Estado en ciertas políticas como de mayores relaciones intrafirmas; y la tercera (1985-presente) donde las políticas de corte neoliberal manifiestan un alejamiento del Estado en la relación capital/trabajo, desintegración de sindicatos y fuerte competencia intrafirma a nivel local e internacional.

Este sector está compuesto por dos grandes segmentos: la industria terminal y de autopartes. Ambas, integradas por empresas de distintos tamaños que pueden ir desde multinacionales con tecnología de punta, inversión y desarrollo, etc., a locales con mano de obra no especializada y tecnología precaria. La cadena productiva, a su vez, se encuentra configurada de la siguiente manera: primer nivel, ensambladoras de origen trasnacional; segundo nivel, subensambles o autopartes importantes en su mayoría multinacionales que establecen, con las primeras de ellas, contratos de cooperación. En un tercer nivel, autopartes pequeñas mayoritariamente locales que abastecen a autopartes de segundo nivel. Por último, micronegocios de materias primas o autopartes locales de baja productividad y tecnología básica. 
Las características de este encadenamiento productivo, según Ramírez (1995 citado en Carrillo 1997:10-11) se basan principalmente en cinco movimientos:

1. Just in time y controles de calidad.

2. Fuerte relación intrafirma en complejas transacciones de productos e insumos.

3. Fuerte jerarquización del proceso productivo basado en una desintegración de firmas grandes (flexibilidad del proceso productivo), dando importancia a la relación intrafirmas.

4. La misma concentración del proceso productivo acarreó una importante redistribución geográfica del sector automotriz, instalándose preferencialmente (sobre todo después del Tratado de Libre Comercio de América del Norte) en la frontera norte (y centro) de México.

5. La base de la cadena productiva y los fiscalizadores de calidad son en un ciento por ciento las ensambladoras de primer nivel; sin embargo, la dirección de ellas no es precisamente la gerencia local (residente en México), sino más bien las casas matrices de cada una (Estados Unidos, Alemania, Japón, etc.).

Para el año 1994, la industria automotriz mexicana ocupaba 455.800 empleados, de los cuales, las plantas terminales (ensamblaje) representaban el 14,4 por ciento, las maquiladoras de autopartes el 28,4 por ciento, los proveedores nacional de autopartes el 39,6 por ciento, y los distribuidores el 1,6 por ciento (Secofi 1995 citado en Carrillo 1997:19). Para el período 2005, acaparó 500.000 empleos directos, que se tradujo en 1,6 por ciento del empleo nacional y 18 por ciento del empleo manufacturero; aportó, a su vez, el 2,5 por ciento del PIB nacional y un 16 por ciento del manufacturero. Alcanzó, en el mismo período, un 19 por ciento del total de las exportaciones totales, 21 por ciento de las manufacturas y 11 por ciento de las importaciones totales.

Entre los años 1994 y 2002, entraron por efecto de Inversión Extranjera Directa 11.000 millones de dólares para la industria automotriz mexicana, sobre todo para las empresas terminales y proveedores de primer nivel, originariamente desde Estados Unidos (50 por ciento), Canadá ( 7 por ciento), Japón ( 26,5 por ciento), y Europa (Alemania: 8 por ciento, España: 2,3 por ciento). Fruto de ello, la producción de vehículos aumentó considerablemente: por ejemplo, para pasajeros pasó de 600.000 unidades, en 1990, a cerca de un 1.000.200 en 2002, y de camiones de 200.000 a 634.000 unidades en el mismo período. 
Sin embargo, es preciso aclarar que los efectos de la Inversión Extranjera Directa distinguen entre la situación de las empresas terminales como de las autopartes. Así, por ejemplo, en la década de 1990 las primeras elevaron su productividad laboral en 57 por ciento, su valor agregado en 59 por ciento y su empleo en 5 por ciento. Las segundas, diferenciadas en maquiladoras y no maquiladoras, arrojaron los siguientes resultados: las últimas, incrementaron su productividad laboral en 11 por ciento, su valor agregado en 39 por ciento y su empleo en 33 por ciento; mientras que las primeras elevaron su productividad laboral en solo 8 por ciento, su valor agregado en 52 por ciento y su empleo en 52 por ciento (Mortimore y Barrón 2005:20).

Así, entre los años 1985 y 2002 la industria automotriz mexicana se transformó en la novena plaza más importante del mundo, al pasar de menos de 400.000 unidades producidas (destinadas al mercado interno, preferentemente) a casi 2 millones, con fuertes propensiones a la exportación ${ }^{6}$ (75 por ciento aproximadamente de la producción total). Sin embargo, a pesar de posicionarse a nivel global, las diferencias internas acusan una situación desigual y jerárquica entre empresas locales y extranjeras. A continuación se pasa revista a la industria terminal y de autopartes en relación de capital de inversión, complejidad productiva, condiciones laborales y alianzas estratégicas.

\section{La industria terminal/ensamblaje en México}

La industria terminal en México la componen empresas como Ford, Chrysler, General Motors, Nissan, Volkswagen, Toyota, entre otras. Estas concentran aproximadamente la totalidad del ensamblaje de vehículos. Para el año 1997, esta industria dió empleo a alrededor de 60.000 personas (4 por ciento del empleo manufacturero) con una producción cercana al 7 por ciento del PIB manufacturero reflejado en 14.000 millones de dólares, aproximadamente. A su vez, mientras el PIB manufacturero creció a una tasa promedio anual del 3,1 por ciento entre los años 1990 y 1997, la tasa que registró la industria terminal en México fue de 7,2 por ciento (Brown 1997).

6 Las estructura de exportaciones automotrices en porcentajes entre los años 1980 y 2000, es la siguiente: de vehículos en 1980 era de 31,2 por ciento, en 1994 de 56,4 por ciento y en 2000 de 66,2 por ciento; de motores de 7,3 por ciento, 16,4 por ciento y 6,6 por ciento; y de autopartes de 58,6 por ciento, 24,3 por ciento y de 23,3 por ciento, propiamente tal (Mortimore y Barrón 2005:21). 


\section{Cuadro $\mathrm{N}^{\circ} 1$}

Industria automotriz de ensamblaje de México, PIB

Tasa de crecimiento en por ciento

\begin{tabular}{|c|c|c|c|}
\hline Año & $\%$ & Año & $\%$ \\
\hline 1968 & 20,4 & 1988 & 32,8 \\
\hline 1972 & 13,6 & 1992 & 11,9 \\
\hline 1976 & $-10,7$ & 1996 & 41,0 \\
\hline 1980 & 14,2 & 2000 & 25,2 \\
\hline 1984 & 31,0 & 2004 & 8,5 \\
\hline
\end{tabular}

Fuente: Sosa 2005:203

Previo al año 1992, la industria terminal en México estaba abocada principalmente a la venta de vehículos en el mercado local. Luego, a partir de 1994, con la puesta en marcha del Tratado de Libre Comercio de América del Norte y previas reestructuraciones, comenzó la exportación de vehículos de manera masiva hacia Estados Unidos, Europa, Asia y América del Sur, respectivamente. Para el año 1997 las exportaciones aumentaron llegando a más de 950.000 unidades vendidas, 66 por ciento más que en 1994 (Vicencio 2007:232). Ya para el período 2004, logró superar la barrera del millón de unidades vendidas, la cual nuevamente se logró incrementar en un 3 por ciento al año siguiente, obteniendo con ello una marca histórica en la producción de automóviles en México.

\section{La industria de autopartes mexicana}

La industria de autopartes mexicana nace en el período ISI entre los decretos de 1962, 1972 y 1977, principalmente. No obstante, es bajo el dominio y dirección de las propias ensambladoras a partir de coinversiones (en algunos casos) con empresas locales o a través de la figura de imposición productiva, en que estas surgen y se mantienen. Los contratos celebrados anteriores al decreto de 1977 entre las industrias terminales y las autopartes tenían como base de negociación el precio del producto, impuesto generalmente a consideración de la ensambladora. Posteriormente los contratos, si bien no se modificarán con las autopartes de $3^{\circ} \mathrm{y} 4^{\circ}$ nivel, sí cambiarán con las de $2^{\circ}$ nivel. No obstante ello, las autopartes locales, al no estar incluidas en el proceso productivo, la integración de tecnología avanzada fue escasa. Por ende, tampoco hubo grandes cambios organizacionales. Luego, a través de la flexibilización que empezara paulatinamente en la década de 1980, los contratos entre ambas industrias comenzaron una carrera de cambio incluyendo ahora diseño, tecnología, servicio y competitividad (Helper 1991; Sturgeon y 
Florida 1997 citados en Brown 1997:12). Sin embargo, ello solo ocurrió con proveedoras de $1^{\circ}$ nivel y, escasamente, con las de $2^{\circ}$ nivel. En el caso de las primeras, también de capital extranjero, preexistía una relación entre ensambladora y proveedora en sus respectivas casas matrices. En el caso de las segundas, siendo en su mayoría empresas locales con cierta coinversión extranjera, abastecerán a las proveedoras de primer nivel, pero la relación contractual prevista entre ellas no llega a ser igual al primer caso. ${ }^{7}$

En el caso de los proveedores, existe una estratificación (Mortimore y Barron 2005:15) en sus funciones que puede ser esquematizada de cuatro formas:

1. Proveedores integrados: ofrecen a las ensambladoras un amplio espectro de servicio como paneles de instrumentos integrados.

2. Proveedoras de sistemas: ofrecen sistemas conformados por múltiples componentes (como los frenos).

3. Proveedoras de componentes: proveen de funciones críticas y componentes intensivos de know-how con fuerte capacidad de ingeniería como los motores auxiliares.

4. Proveedores de productos estandarizados: empresas tradicionales de proveeduría como lo son los conectores.

Los cambios en la estructura productiva y el encadenamiento consecutivo de una flexibilidad emergente comienzan a impactar a empresas proveedoras de $1^{\circ}$ nivel, señalando una nueva estrategia organizacional que tiene como finalidad, según establecen Cross y Gordon (1995 citados en Brown 1997:23), "dejar en manos de estos proveedores la organización de la cadena de proveeduría”. Se materializa este ejercicio en los contratos celebrados entre la terminal y las proveedoras de primer nivel que, en su mayoría, son contratos a largo plazo que estipulan como requerimientos y obligaciones de la proveedora disminuir precios de productos paralelamente a una mayor calidad de ellos. Es decir, la ensambladora se libera de la elaboración del automóvil y traspasa responsabilidades, para lo que aplica nuevas reestructuraciones y contratos. En caso de fallo de alguna cláusulas, los contratos por lo general conciertan penalidades monetarias, cuando no su finiquito.

También se encuentran casos en que la misma proveedora de primer nivel, con el tiempo, adquiere sus propias proveedoras (que incluyen maquila) de $2^{\circ}, 3^{\circ}$ y $4^{\circ}$ nivel, concretando, de esta manera, encadenamientos productivos complejos bajo un mismo sello de primer nivel con certificaciones internacionales (ISO 9000, SQ 9000, etc.). En otros términos, la proveedora subensambla gran parte del vehículo que tendrá el sello característico de la ensambladora final pero que, en realidad, gran parte de su trabajo está definido en las proveedoras. 
Actualmente, hay alrededor de 600 empresas de autopartes en territorio mexicano, de las cuales 230 son consideradas grandes, 160 medianas y 200 pequeñas y/o micro. En su conjunto, generan el 89 por ciento del empleo directo de la industria automotriz y el 41 por ciento del total del empleo generado de la cadena automotriz; además, cubren un 9 por ciento de las exportaciones del sector manufacturero. Del total de ellas, 450 son proveedores de equipos originales y de estos, solo el 33 por ciento son consideradas como proveedores de primer nivel (Vicencio 2007:234).

No obstante, existe una categoría que a veces escapa a los esquemas propuestos, pues muchos de ellos son catalogados como "proveedores satélites" (Álvarez 2002). Esto es, su función es importar y distribuir autopartes. Así, entonces, Bancomext reporta que hay aproximadamente 350 empresas proveedoras de primer nivel que elaboran autopartes, además de distribuirlas. En cuanto a las autopartes de $2^{\circ}, 3^{\circ}$ y $4^{\circ}$ nivel, registra alrededor de 1.500 (incluyendo maquiladoras), las cuales estarían concentradas sobre todo en las regiones centro y norte del país. De las proveedoras de $4^{\circ}$ nivel, el 97 por ciento serían pequeñas y todas de capital mexicano (Villarreal y Villegas 2007:8). Por otro lado, la Encuesta Industria Mensual muestra que, en 2008 (marzo), en la industria automotriz de proveedores de autopartes trabajaban 73 por ciento de los obreros, mientras que el 27 por ciento restante lo hacía en empresas ensambladoras. Respecto el salario promedio, los obreros de las autopartes (de $1^{\circ} \mathrm{y} 2^{\circ}$ nivel principalmente) llegaba a $\$ 5.000$, mientras que el de las ensambladoras alcanzaba los $\$ 8.600$ mensuales. Por el lado de las prestaciones sociales promedio, para un obrero en una empresa de autopartes fluctuaba por los $\$ 2.700$, y en las ensambladoras finales del orden de $\$ 3.500^{8}$ (Martínez 2008:12-13).

\section{Cuadro $\mathrm{N}^{\circ} 2$}

Industria automotriz de autopartes de México, PIB

Tasa de crecimiento en por ciento

\begin{tabular}{|c|c|c|c|}
\hline Año & \% & Año & $\%$ \\
\hline 1968 & 11,7 & 1988 & 20,7 \\
\hline 1972 & 9,9 & 1992 & $-0,2$ \\
\hline 1976 & $-6,3$ & 1996 & 20,2 \\
\hline 1980 & 10,5 & 2000 & 10,6 \\
\hline 1984 & 22,8 & 2004 & 4,8 \\
\hline
\end{tabular}

Fuente: Sosa 2005:203

89,17 pesos mexicanos equivalen a 1 US (2010). 
El cuadro presenta la variación en la tasa de crecimiento de la industria automotriz. Se desprende e interpreta de él una situación que se presenta como frágil, pues la extrema dependencia de la industria de autopartes a los movimientos del mercado mundial, sobre todo del estadounidense, crea la ilusión en ciertos momentos de desarrollo (años 1984, 1988, 1996, 2000, por ejemplo), cuando por el contrario señala complejas relaciones empresariales donde la industria maquiladora explica de mejor manera tanto el crecimiento como el decrecimiento.

\section{Industria maquiladora de autopartes}

Si bien su actividad comienza entre 1965 y 1972, y en los años 1980 tiene un despliegue mayor, no es hasta el Tratado de Libre Comercio de América del Norte, firmado el año 1994, y la posterior devaluación del peso mexicano en el mismo período, que la maquiladora llega a ser un elemento relevante para toda la economía norteamericana, incluyendo a Estados Unidos y Canadá, propiamente tal.

Mientras que México vivió la crisis económica más severa en los últimos sesenta años, las exportaciones manufactureras continuaron creciendo a tasas elevadas, aumentando considerablemente su participación en las exportaciones no tradicionales. Por ejemplo, en 1995 las exportaciones petroleras fueron de 7,4 mil millones de dólares y las de maquiladoras de 4,96 mil millones (Carrillo 1997:218 citado en Novick y Gallart 1997).

En este sentido, además del tradicional uso de mano de obra barata o no calificada en diferentes áreas, las maquiladoras mexicanas comenzaron una alta competencia en la atracción de una mano de obra altamente calificada (ingenieros provenientes de institutos profesionales que surgieran a raíz de cluster o semi-cluster industriales en ciudades como Monterrey, Puebla, etc.). Las maquiladoras pueden elaborar tanto productos finales (como televisores o ropa), intermedios (arneses para la industria automotriz) o como refacciones (por ejemplo, válvulas).

No obstante ello, un hecho que ha sido característico de las empresas maquiladoras en México y que fuera concebida como una importante "ventaja competitiva" es, sin duda, los bajos costos totales respecto a sus homólogas (particularmente) estadounidenses. Por ejemplo, un ingeniero en Estados Unidos en la misma maquiladora con igual calificación, puesto y antigüedad, gana dos o tres veces más que en cualquier autoparte de México. Respecto de la mano de obra no calificada y semicalificada, esta diferencia llega incluso a 10 veces (Carrillo 1997:220-22 citado en Novick y Gallart 1997). 
Se debe tener presente, por otro lado, que dentro de las mismas industrias maquiladoras la estratificación salarial persiste y se acrecienta aún más en un movimiento descendiente que involucra en lo más alto a administradores con mejores salarios, técnicos en un escalafón medio hasta llegar a los trabajadores directos con los salarios más bajos de la estructura interna de la maquiladora, como de todo el sistema automotriz (Carrillo y Gomis 2003). Sin embargo, para el año 2000, las empresas maquiladoras llegaron a emplear a más de 1.300.000 trabajadores (Carrillo y Gomis 2003:320). Este número de empleos ha ido decreciendo desde entonces, no obstante, se mantiene oscilante al millón de empleos.

Para el período 2005, las exportaciones de este sector representaron alrededor del 56 por ciento del total de exportaciones manufactureras y generó aproximadamente un 40 por ciento del empleo en todo el sector. Con ello, se vislumbra un subsector con alta contrata de personal pero a bajos costos totales, sobre todo salariales. Se crea, de esta manera, un problema: a mayor exportación de autopartes será mayor la cantidad de mano de obra contratada, pero con escalas bajas de salario y tasa de crecimiento, pues sus productos generan escaso valor.

\section{VOLKSWAGEN DE MÉXICO: ANTECEDENTES DEL PROBLEMA DE LA FLEXIBILIAD}

Durante un largo período, VWM fue la empresa líder en venta de vehículos en México. Por ello para el año 1965, bajo el modelo ISI, traslada toda su planta a la localidad de Puebla para dedicarse a la creación integral de automóviles con mira exclusiva al consumo local, puesto que antes era la importación y distribución su principal área comercial.

Luego, en la década del 80 a través del incentivo de una política tendiente a la exportación en México, decide abrir nuevas plantas que serían exclusivamente para exportación hacia sus otras sucursales en Estados Unidos (Pries 2000:164). Este movimiento transformador y con clara tendencia exportadora, tiene en los años 1992 y 1993 su punto cumbre, pues se configuran allí una serie de elementos que para Pries (2000:167-68) denotan no solo un cambio industrial, sino también organizacional (subjetivo). Esta situación se da bajo cuatro elementos:

1. La creación del Golf A3, con todos sus cortes técnicos, organizativos y de trabajo correspondientes. Este nuevo modelo fue lanzado casi en forma simultánea con Alemania, hecho fundamental en la historia de VWM, puesto que se 
pasó a considerar a la sucursal ya no como tal, sino como parte fundamental de las proyecciones industriales y económicas de la firma VW. Así, en el año 1995, VWM produce el modelo New Beetle exclusivamente en Puebla-México.

2. En 1992 se produce un enfrentamiento dentro del sindicato en relación a los cambios productivos. Resultó de este ajuste una nueva forma de relaciones en la empresa y un reequilibrio de las relaciones de poder a favor de VWM.

3. El recambio interno a niveles organizacionales no solo afectó al sindicato, sino también a personal de confianza y gerentes a quienes se les redujo las plazas a ocupar.

4. Debido a los cambios organizacionales y la generación de nuevos modelos basados en la plataforma A4 (Golf/Jetta y New Beetle), VW de Alemania le insiste a sus propios proveedores de alta tecnología instalarse en Puebla-México. A consecuencia de ello, se da una migración masiva de proveedores de autopartes de $1^{\circ}$ y $2^{\circ}$ nivel..$^{9}$ El siguiente paso fue la integración de la figura de subcontratación en servicios y otros rubros.

VWM llegó a tener como máximo una plantilla de más de 20.000 empleados (20.249 en 1990). Para 1994, esta se redujo a unos 11.000 y actualmente oscila por los 12.800 trabajadores, aproximadamente. ${ }^{10}$ Sin embargo, y por ser considerada cluster industrial, la gran mayoría de las empresas asentadas en Puebla o localidades colindantes dependen de VWM, por lo que se estima que esta genera unos 80.000 empleos indirectos (Montiel 2002:3). Es decir, su impacto en el empleo se aproxima a la cuarta parte del PEA de Puebla (El Universal citado en Montiel 2002).

Por otro lado, el proceso de restructuración productiva, que se intensificó a comienzo de 1990, consideró que la misma VWM vendiera prensas a subcontratistas locales, pues así lo estipulaban ciertos decretos que avalaban la exportación, siempre bajo cláusulas de no abandono a la industria proveedora nacional. Con ello, se efectuó también un traspaso de personal hacia las mismas proveedoras que significó, normalmente, una reducción de los niveles salariales del orden de un 50 por ciento en quienes fueron dirigidos o enviados hacia las distintas proveedoras.

En comparación con los salarios de los trabajadores de WVM, los obreros y empleados de los proveedores en el parque FINSA ganan la mitad o hasta una tercera parte. To-

9 Para el año 1997 existían alrededor de 80 empresas proveedoras alemanas en México, específicamente en Puebla y su alrededores (Pries 2000:176).

10 Clasificación aproximada: personal de confianza (3.000), trabajadores sindicalizados (9.000) y trabajadores eventuales (variables de acuerdo a coyuntura económica), según su propia página web (www.vw.com.mx). 
mando la industria automotriz de la región en su conjunto, de esta manera, el outsourcing también significa un muy tangible downgrading (es decir: nivelación hacia abajo) de las condiciones de trabajo (Pries 2000:176).

Terminando la década de 1990, en el plano interno de VWM el personal técnico y de ingeniería (personal de confianza) percibía un salario promedio de $\$ 4.000$ mensuales más prestaciones, el resto de obreros sindicalizados percibían entre los $\$ 1.200$ y \$2.000 (Juárez 1999:16). Otros obreros perciben los mismos \$1.200 y \$2.000 mensualmente, pero sin prestaciones sociales; son los llamados trabajadores eventuales ${ }^{11}$ que por situación rígida de flexibilización fungen como reserva contingente: ante recesiones son los primeros en ser despedidos o ante una alta demanda son recontratados, tomando en cuenta un escalafón ad hoc de antigüedad.

En el desarrollo organizacional de reestructuración productiva, VWM desarrolla y madura el concepto de plataforma giratoria, la cual se especializará en productos específicos pero contará con diversas versiones de acuerdo a los distintos mercados. La plataforma giratoria se sustenta en el desarrollo de modernos encadenamientos productivos donde existe una alta cooperación ${ }^{12}$ intra a interfirmas (García y Lara 2006).

El encadenamiento productivo industrial y la reestructuración organizacional que propuso la firma automotriz VW, tanto en México como en sus otras sucursales bajo la idea de producción flexible, trajo consigo la inclusión de más actores en el diseño y creación del automóvil, con lo que para el año 2010 VWM cuenta con un número cercano a 210 proveedores directos (para 1960 contaba con 20 proveedores), de los cuales, el 82 por ciento son filiales de grupos globales como Johnson Controls, Lear Corp., Magna, entre otros, y todos ellos se encuentran en el parque industrial FINSA. Ellos conforman los niveles $1^{\circ}$ y $2^{\circ}$ de proveedores. Algunos de ellos, cabe destacar, incluyen sus propias maquilas, como es el caso de los proveedores de asientos Lear Corporation. ${ }^{13}$

11 El Instituto Mexicano del Seguro Social (IMSS), a través del comunicado número 122 (03/09/2010), informó que al 31 de agosto de 2010 el número de trabajadores permanentes asegurados había ascendido en un 3,69 por ciento (425.189 empleos) respecto el período 2009, llegando a casi 13 millones de trabajadores permanentes urbanos. Los eventuales asegurados, por su lado, registraron un incremento de un 14,15 por ciento (224.239 empleos) respecto a agosto del 2009, totalizando así en un millón 800 mil empleos, aproximadamente (www.imss.gob.mx).

12 Pries (2000) afirmaque en el caso de Volkswagen y sus proveedores de $1^{\circ}$ nivel la relación intra se debe a constantes presiones que recibían estas para que se posicionaran en Puebla-México, por lo que más que colaboración o cooperación ( $p u l l$ ) se habría producido una constante presión (push) en la relación intra e interfirmas.

13 Véase Lara, García y Trujano (2003); García y Taboada (2007). 
Cuadro $\mathrm{N}^{\circ} 3$

Autopartes en el parque industrial FINSA

\begin{tabular}{|c|c|c|c|}
\hline $\mathbf{N}^{\circ}$ & Empresa & Producto & $\begin{array}{l}\text { Origen de } \\
\text { capital }\end{array}$ \\
\hline 1 & $\begin{array}{l}\text { Alfred Engelmann de } \\
\text { México S.A. de C.V. }\end{array}$ & $\begin{array}{l}\text { Almacenaje, espejos y tapa } \\
\text { para combustible }\end{array}$ & $\begin{array}{l}\text { No hay dato } \\
\text { (n.d.) }\end{array}$ \\
\hline 2 & $\begin{array}{l}\text { American Car Equipment } \\
\text { S.A. de C.V. }\end{array}$ & Arneses eléctricos & Española \\
\hline 3 & Grupo Antolín & Toldos & Española \\
\hline 4 & $\begin{array}{c}\text { Auto Ensambles y Logística } \\
\text { S.A. de C.V. }\end{array}$ & $\begin{array}{c}\text { Autopartes y servicios de } \\
\text { ensamble y logística }\end{array}$ & N.d. \\
\hline 5 & $\begin{array}{l}\text { Becker Group México S.A. } \\
\text { de C.V. }\end{array}$ & Paneles para puertas y sombrereras & N.d. \\
\hline 6 & Bosal de México & Sistema de escape & Francesa \\
\hline 7 & Cisa & Asientos automotrices & Estadounidense \\
\hline 8 & Decoplast, S.A. de C.V. & Molduras y fascias & $\begin{array}{l}\text { Mexicano- } \\
\text { canadiense }\end{array}$ \\
\hline 9 & $\begin{array}{l}\text { Delphi Automotive System } \\
\text { S.A. de C.V. }\end{array}$ & Sistema de audio & Estadounidense \\
\hline 10 & Duroplast S.A. de C.V. & Partes plásticas para tableros & Mexicana \\
\hline 11 & Electro óptica S.A. de C.V. & Faros, calaveras, manijas y defensa & $\begin{array}{l}\text { Alemán- } \\
\text { mexicano }\end{array}$ \\
\hline 12 & $\begin{array}{l}\text { Faurencia-Duroplast S.A. } \\
\text { de C.V. }\end{array}$ & Tableros de control & $\begin{array}{l}\text { Franco- } \\
\text { mexicano }\end{array}$ \\
\hline 13 & Engelmann & Almacenes de espejos retrovisores & Alemana \\
\hline 14 & Exel & Logística & Española \\
\hline 15 & $\begin{array}{l}\text { Findlay Industries de México } \\
\text { S.A. de C.V. }\end{array}$ & $\begin{array}{c}\text { Sombrereras, recubrimientos, } \\
\text { fundas, parasoles, paneles de } \\
\text { puertas y toldos }\end{array}$ & Estadounidense \\
\hline 16 & Fer Mexicana s de RL de C.V. & Inyección de plástico & Alemana \\
\hline 17 & Gedas & $\begin{array}{l}\text { Comunicación y sistema de control } \\
\text { de producción }\end{array}$ & Alemana \\
\hline 18 & $\begin{array}{c}\text { Johnson Controls Automoti- } \\
\text { ve de México S.A. de C.V. }\end{array}$ & $\begin{array}{l}\text { Tapizado de asientos y estructuras } \\
\text { metálicas, módulos para asientos }\end{array}$ & Estadounidense \\
\hline 19 & Hella Fronted S.A. de C.V. & Ensamble de parte frontal & Alemana \\
\hline
\end{tabular}




\begin{tabular}{|c|c|c|c|}
\hline 20 & $\begin{array}{l}\text { Kautex Textrom de México } \\
\text { S.A. de C.V. }\end{array}$ & Tanques para gasolinas & $\begin{array}{l}\text { Alemana- } \\
\text { estadounidense }\end{array}$ \\
\hline 21 & Kayser México S.A. de C.V. & $\begin{array}{l}\text { Abrazaderas de sostén, bridas de } \\
\text { collarin, bandas planas y mangueras } \\
\text { para frenos }\end{array}$ & Alemana \\
\hline 22 & Kingtec & Almacenes de pinturas & Costa Rica \\
\hline 23 & Kratzer & Sistema de comunicaciones & Alemana \\
\hline 24 & $\begin{array}{l}\text { Lear Corporation de México } \\
\text { S.A. de C.V. }\end{array}$ & $\begin{array}{l}\text { Ensamble de asientos para A3 y A4 } \\
\text { y todos los asientos para el Cabrio }\end{array}$ & Estadounidense \\
\hline 25 & $\begin{array}{l}\text { Mahle-Duroplast Sistemas } \\
\text { de filtración S.A. de C.V. }\end{array}$ & $\begin{array}{l}\text { Partes plásticas para sistemas de } \\
\text { filtración }\end{array}$ & $\begin{array}{l}\text { Alemana- } \\
\text { mexicana }\end{array}$ \\
\hline 26 & Meritor Mexicana & Ensamble de puertas & Estadounidense \\
\hline 27 & Mount Vernon & Almacenes de textiles & Estadounidense \\
\hline 28 & Neyr Plásticos S.A. de C.V. & Inyección de plásticos & Francés \\
\hline 29 & $\begin{array}{l}\text { Peguform Hella México S.A. } \\
\text { de C.V. }\end{array}$ & Defensas, molduras y fascias & $\begin{array}{l}\text { Alemana- } \\
\text { mexicana }\end{array}$ \\
\hline 30 & Refa Mexicana S.A. de C.V. & Estampados y engranes & Canadiense \\
\hline 31 & Rhenus Automotive Logistic & Servicios de Logística & Alemana \\
\hline 32 & SAS & Servicios de logística & Española \\
\hline 33 & Secorisa & $\begin{array}{c}\text { Consignación y distribución } \\
\text { de autopartes }\end{array}$ & Alemana \\
\hline 34 & Seglo S.A. de C.V. & $\begin{array}{c}\text { Servicios de logística } \\
\text { y administración }\end{array}$ & Alemana \\
\hline 35 & $\begin{array}{l}\text { Socop de México S.A. } \\
\text { de C.V. }\end{array}$ & Luces interiores & Francesa \\
\hline 36 & Sekurit & Parabrisas & Francesa \\
\hline 37 & $\begin{array}{l}\text { Sommer Allibert-Duroplast } \\
\text { México S.A. de C.V. }\end{array}$ & $\begin{array}{c}\text { Tableros y partes interiores } \\
\text { de puertas }\end{array}$ & Estadounidense \\
\hline 38 & Transvav S.A. de C.V. & Partes plásticas & Estadounidense \\
\hline 39 & $\begin{array}{c}\text { TRW Sistemas de } \\
\text { Direcciones S.A. de C.V. }\end{array}$ & $\begin{array}{l}\text { Ensamble de suspensiones y } \\
\text { sistemas de cajas de dirección }\end{array}$ & Estadounidense \\
\hline 40 & Trunkey & $\begin{array}{c}\text { Sistema de comunicación } \\
\text { vía satélite }\end{array}$ & N.d. \\
\hline 41 & VW Garantías & Almacén de partes automotrices & Alemana \\
\hline
\end{tabular}

Fuente: García y Lara 2006:8-9 
Para conectar y a su vez mantener control e información ininterrumpida de todos los productos requeridos, VWM utiliza el sistema JIT/K que se encuentra establecido en los propios contratos celebrados con y entre cada empresa. De manera que el sistema modular y flexible al requerir todo a tiempo y sin fallas, VWM contempla un sistema de evaluación de calidad que, además, procura sanciones en caso de anomalías en los tiempos de entrega o fallas del producto: por ejemplo, si los pedidos dentro de 45 a 90 minutos, dependiendo de la ubicación, no llegan a la planta ensambladora, VWM puede sancionar a sus proveedores con multas que pueden ir desde los 600 a los 1.000 dólares el minuto de retraso (Martínez 2008).

De esta manera, VWM asegura la producción y no corre riesgo alguno para mantener un estándar de ventas de acuerdo a las metas establecidas sin la necesidad de incurrir en la pérdida. A su vez, le permite jerarquizar su estructura de proveedurías: las empresas "A" se caracterizan por: a) relación con VW a través de contratos globales, b) experiencia para producir o subensamblar productos complejos, y c) capacidad para desarrollar tecnología y logística para nuevos modelos. Las empresas "B" se caracterizan por una producción de mediana complejidad que, para ello: a) cuentan con menor experiencia que las empresas "A", b) tienen una participación de menor grado en la producción que encabeza VWM, y c) son objeto de auditorías continuas de calidad y productividad. Por último, están los proveedores "C" que, por lo general, se encargan de maquilar productos de muy baja complejidad, tienen baja capacidad financiera y están bajo constante amenaza de finiquito de contratos que, por cierto, tienen plazos definidos por empresas mayores.

Todo este encadenamiento tuvo fuertes repercusiones en el sindicato de VWM, pues conllevó una reducción de personal y su traspaso a otras proveedoras con reducciones de salario; además de una reorganización interna donde la competencia y polivalencia agudizaron los problemas de representatividad y negociación que el sindicato venía presentando tiempo atrás. Es menester, por ello, revisar brevemente su historia y los sucesos que marcaron la puesta en marcha del proceso de flexibilización y las consecuencias que trajo esta práctica.

\section{Sindicato de Volkswagen de México: conflictos internos organizativos}

Para Pries (2000) la historia del sindicato se divide, básicamente, en un antes y un después de 1992. En esta ruptura se encuentra lo que es conocido como el programa Nueva Salida, que grossomodo retomó las prácticas flexibles del modelo japonés y destacó el incremento de la competencia al interior del consorcio (Montiel 2007). Por otra 
parte, como establece Montiel (2007), este programa contempla la ampliación de una perspectiva más autoritaria que toma como punto de referencia una constante presión en la relación local entre la gerencia y el consejo de trabajadores.

Se presentó, en este período, un conflicto tanto en el sindicato como en su relación con VWM a raíz de un acuerdo firmado entre la dirigencia del sindicato y la empresa que implicaba cambios en el sistema productivo, como la integración de la subcontratación en grandes proporciones. En consecuencia, el Contrato Colectivo de Trabajadores hasta el momento vigente quedó completamente obsoleto, por considerar puntos que no permitían tales cambios.

Estalla el conflicto debido a que el acuerdo al cual llega el Comité Ejecutivo del sindicato con la empresa fuera de manera privada, sin previa consulta a los trabajadores. Este hecho hizo que el sindicato se dividiera en dos facciones irreconciliables que, por un lado, enfrentó las dos columnas que previamente disputaran las elecciones del mismo comité y otorgó, por el otro, el escenario propicio para que VWM, de manera veloz y precisa, aprovechara de remover piezas y reformara la estrategia de cambio productivo que hacía falta para la nueva era industrial.

La gerencia de VWM, sin embargo, necesitaba tiempo para afinar detalles del cambio productivo, por lo que en medio de la crisis se estableció un paro patronal apoyado y amparado (debido a la repercusión del asunto) por los gobiernos estatal y federal que, después de dos meses, fallaron a favor de la empresa en el uso legítimo del paro y el cambio organizativo planificado en desmedro de las continuas demandas del sindicato (Montiel 2007). Todo el conflicto culminó con un nuevo Contrato Colectivo de Trabajadores modificado por VWM sin consulta ni participación colectiva del sindicato.

El Contrato Colectivo de Trabajadores, así, fue modificado en 53 de las 74 cláusulas que lo constituían. Se mantuvieron algunos beneficios previstos en el anterior (comida, jornada laboral, entre otras), no obstante, los cambios fueron en directa relación a un detrimento jurisdiccional del sindicato. Por ejemplo, empleados de alta calificación pasaron a ser personal de confianza de la empresa, por ende, su renuncia al sindicato era inmediata y necesaria según la empresa. Asimismo, quedó a discreción de la empresa cubrir vacantes, al igual que la posibilidad de movilidad laboral interna. Por otro lado, se creó la figura cliente-proveedor para el sistema de trabajo, las reuniones de altos ejecutivos y gerenciales de VWM ya no emitirían informes de producción al sindicato y se suprimió el derecho a denunciar al personal de confianza a los trabajadores sindicalizados o eventuales, entre otras (Montiel 2007:35). 
Este nuevo Contrato Colectivo de Trabajadores también introdujo cambios al mismo sindicato.

Acerca de la restructuración del sindicato, que constituye otro punto central de esta experiencia de cambio, por una parte se amplió el número de integrantes del Comité Ejecutivo (de 10 a 15) y del tiempo de su gestión (de tres a cuatro años); por otra, disminuyó el número de participantes en las comisiones: la que revisa el contrato de 56 - más los delegados que en total sumaban 112 personas- a 30, y la del salario de 30 a 20 (Montiel 2007:38).

Otros cambios internos también se dieron en la representación de cada sección del sindicato con el Comité Ejecutivo: de 17 secciones se pasó a ocho, quedaron 11 secretarios auxiliares en representación de 1.100 trabajadores cada uno, hecho que contrasta con los 214 seccionales anteriores que representaban alrededor de 100 trabajadores cada uno (Montiel 2007).

Por otro lado, era costumbre que cada cuatro años el Comité Ejecutivo electo pedía la expulsión y despido del comité anterior, por lo que una especie de guerrilla interna se daba dentro del sindicato en periodos electorales. Así, guerras declaradas en formato de plantillas dejaban a trabajadores, por un lado, en condiciones completamente atomizadas en voto y representación, y por el otro, como un bloque dividido frente a la empresa. ${ }^{14}$

Sin embargo, esta situación parece estar cambiando por dos factores: primero, la baja tendencia de ventas por la recesión estadounidense y segundo, nuevas reestructuraciones internas, las cuales han revitalizado en el sindicato una organizativa política. Montiel (2007) asegura que las empresas terminales como VWM tradicionalmente han enfrentado las variaciones del mercado con una política simple de despido y contratación; por ello, la negociación colectiva del sindicato actual entra a fraguar como una nueva etapa del sindicalismo automotriz y mexicano del siglo XXI.

Ejemplo de ello sería el año 2001: a raíz de una menor demanda automotriz desde Estados Unidos, la empresa comunicó el despido de entre un 8 y 12 por ciento de sindicalizados, el total de los eventuales (1.800, aproximadamente) más 400 trabajadores. Ante

14 Este hecho, sin embargo, no es novedad dentro de la historia del sindicato. En 1972 se descubrió que en el interior del Comité Ejecutivo y del sindicato habían personas de confianza de VWM y del Partido Revolucionario Institucional (Montiel 2007). Otros hechos irregulares, en torno al conflicto de 1992, es que una vez solucionado, a cada trabajador se le obligó a firmar una carta donde "renunciaban al ejercicio de sus derechos laborales y constitucionales en caso de demanda a la empresa” (Montiel 2007:36). 
esta situación, el Comité Ejecutivo del sindicato llevó a cabo una consulta de base para una nueva propuesta en respuesta a la de VWM (Montiel 2007), la cual estaba enfocada solo a trabajadores sindicalizados. La consulta tuvo dos opciones: a) reducción de jornada, reducción de salarios y revisión contractual del Contrato Colectivo de Trabajadores adelantada, y b) despido de 1.350 trabajadores eventuales y otros de base. El resultado de la votación ${ }^{15}$ fue el despido, por un lado, de trabajadores eventuales (900 trabajadores de inmediato) y otro tanto de base, más un programa de retiro voluntario de acuerdo a lo estipulado al Contrato Colectivo de Trabajadores.

Entre los alegatos de los trabajadores del por qué la elección de la segunda opción, según el estudio de Montiel (2007), aflora en su mayoría una desconfianza hacia la empresa sobre todo por la tercera parte de la primera opción (revisión anticipada del Contrato Colectivo de Trabajadores) por los recuerdos de 1992. Otro argumento fue que, de ser aceptada la primera opción, ello no significaba el no despido de trabajadores, sino más bien solo de una parte de ellos (es decir, de todas maneras habrían despidos), por lo cual se encontraron confusiones en la propuesta del Comité. Además, se fundamentó que si se bajaba el salario y las prestaciones a más de 10.000 trabajadores por motivos de la recesión estadounidense, este acontecimiento sería copiado por las demás empresas automotrices y podría efectuarse cada vez que se crea que la producción esté a la baja. ${ }^{16}$

\section{2. Últimos conflictos entre VWM y el sindicato}

Bien lejos de las contracciones financieras y recesiones económicas, VW instaló una nueva planta de motores en México, esta vez en Guanajuato (zona centro) en vez de Puebla. Esta política de cambio de escenario refleja, según Juárez, ${ }^{17}$ una estrategia política y económica. Política, debido a que en Guanajuato habría una escasa experiencia sindical y baja industrialización, por lo que las condiciones favorecen la contrata de empleados bajo contratos leoninos. Económica, pues puede reducir aún más los costos de producción (casi en un 100 por ciento) a través de la figura de outsourcing y flexibilidad laboral.

Otra señal que estaría dando VWM al tomar esta decisión, según el mismo autor, sería una estrategia de despotenciar al mismo sindicato de Puebla. Esto se debería a: pri-

15 Los resultados de la votación fueron los siguientes: a favor de la opción (a), 2.215 votos; a favor de la opción (b), 6.325 votos; abstenciones, 1.045 votos (Montiel 2007:9).

16 En Alemania sucedió algo similar en una recesión económica y VW llevó a cabo la misma receta de despido masivo de trabajadores eventuales y sindicalizados, sin embargo, en este caso el sindicato sí acepto la baja de jornada de trabajo, pues el Estado subsidió la parte restante.

17 Milenio, 22/09/2010, http://www.milenio.com/cdb/doc/impreso/8835845 
mero, el sindicato de trabajadores de Guanajuato pertenecería a la CTM, ${ }^{18}$ y segundo, a una supuesta demanda de la empresa en declarar culpable al sindicato en su rigidez para no colaborar con los cambios necesarios en la producción. Esto quiere decir que, ante la negativa constante del sindicato a nuevas flexibilizaciones (como la implementación de un banco de horas), sumado a reiteradas protestas por nuevas alzas de salario (una el año 2009, otra en el 2010), la empresa decide invertir más de 500 millones de dólares en un Estado cercano como lo es Guanajuato.

Varias son las reacciones frente a este hecho. El Consejo de Organismo Empresariales de México declaró como culpable la rigidez del sindicato en el traslado de VWM hacia Guanajuato, haciendo hincapié en los altos costos de mano de obra y prestaciones instaladas en el Contrato Colectivo de Trabajadores (Diario ECO 21/09/2010). Juárez, sin embargo, indica que las prestaciones (incluyendo a la gerencia y trabajadores de confianza) alcanza recién al 4,5 por ciento de los costos de producción de VWM, es decir, su competitividad en el mercado global no sería la verdadera excusa, sino más bien habría sido una política mancomunada entre gobierno y empresa para desarticular resistencias obreras. Esto refleja, a juicio de Juárez, que, en realidad, la alta productividad y competitividad de México en el mercado automotriz sería sobre la base del constante agotamiento del trabajador, pues la industria automotriz en México no produce jubilaciones (Juárez, Milenio 22/09/2010); hecho que el propio Contrato Colectivo de Trabajadores de VWM estipula así.

\section{CONTRATO COLECTIVO DE TRABAJADORES DE VWM: EJEMPLO DE FLEXIBILIDAD LABORAL}

A continuación se presentan algunas características de la flexibilidad laboral aplicada a un Contrato Colectivo de Trabajadores.

18 Filial sindical dependiente del Estado mexicano con la que el sindicato de VWM ya había quebrado relaciones décadas atrás por episodios poco claros en los Contratos Colectivos de Trabajadores. 


\section{Cuadro $\mathrm{N}^{\circ} 6$}

Características del Contrato Colectivo de Trabajadores previo y posterior a 1992

\begin{tabular}{|c|c|c|c|}
\hline $\mathrm{N}^{\circ}$ & Categorías & 1982-1992 & 1992-1994 \\
\hline 1 & $\begin{array}{l}\text { Definición de cargos y } \\
\text { ritmos de trabajos }\end{array}$ & La empresa & La empresa \\
\hline 2 & Movilidad horizontal & $\begin{array}{l}\text { Hasta } 3 \text { días: abierto } 4 \text { a } 30 \\
\text { días. Aviso al sindicato. Más } \\
\text { de } 30 \text { días de convenio }\end{array}$ & $\begin{array}{c}\text { Hasta } 15 \text { días: abierto } 16 \text { a } \\
45 \text { días. Aviso al sindicato. } \\
\text { Más de } 45 \text { días } \\
\text { de convenio }\end{array}$ \\
\hline 3 & Programa de producción & Aviso al sindicato & No existe compromiso \\
\hline 4 & Solución de conflictos & 4 instancias bilaterales & 4 instancias bilaterales \\
\hline 5 & Trabajo en equipo & No contempla & Sí \\
\hline 6 & Integración funciones & No contempla & Sí \\
\hline 7 & $\begin{array}{c}\text { Control estadístico de } \\
\text { procesos }\end{array}$ & No contempla & Sí \\
\hline 8 & Supervisión del trabajo & Personal de confianza & $\begin{array}{c}\text { Autocontrol/personal } \\
\text { de confianza }\end{array}$ \\
\hline 9 & Obligación capacitar & No contempla & Sí \\
\hline 10 & Subcontratación & $\begin{array}{l}\text { Sí. Mantenimiento, servicios, } \\
\text { principalmente }\end{array}$ & Sí. Todas las áreas. \\
\hline 11 & $\begin{array}{l}\text { Ingreso de nuevos } \\
\text { trabajadores }\end{array}$ & Propuesta sindical & Propuesta sindical \\
\hline 12 & Eventuales & Número abierto & Número abierto \\
\hline 13 & Periodo de prueba & 29 días & 30 días \\
\hline 14 & Personal de confianza & De acuerdo a LFT & De acuerdo a LFT \\
\hline 15 & Escalafón & Antigüedad & Solo salario \\
\hline 16 & Cláusula de exclusión & Sí & Sí \\
\hline 17 & $\begin{array}{c}\text { Suspensión por sanción } \\
\text { sindical }\end{array}$ & Sí & Sí \\
\hline 18 & $\begin{array}{c}\text { Obligación de } \\
\text { cubrir vacantes }\end{array}$ & Todas & No existe \\
\hline 19 & Reajustes y despidos & LFT/Aviso al sindicato & LFT/Aviso al sindicato \\
\hline 20 & Jornada semanal & $\begin{array}{l}\text { 10:44 hrs. } \\
\text { 20:42 hrs. } \\
\text { 30:40 hrs. }\end{array}$ & $\begin{array}{l}\text { 10:44 hrs. } \\
\text { 20:42 hrs. } \\
\text { 30:40 hrs. }\end{array}$ \\
\hline
\end{tabular}




\begin{tabular}{|c|c|c|c|}
\hline 21 & Tiempo extra & $\begin{array}{l}\text { Hasta } 9 \text { hrs.: } 200 \text { por ciento } \\
\text { Más de } 9 \text { hrs.: } 300 \text { por ciento } \\
\text { Reglamentado y bilateral }\end{array}$ & $\begin{array}{l}\text { Hasta } 9 \text { hrs.: } 200 \text { por ciento } \\
\text { Más de } 9 \text { hrs.: } 300 \text { por ciento } \\
\text { Decisión de la empresa }\end{array}$ \\
\hline 22 & Vacaciones & $\begin{array}{c}14 \text { a } 20 \text { días } \\
\text { (según antigüedad) }\end{array}$ & $\begin{array}{c}14 \text { a } 29 \text { días } \\
\text { (según antigüedad) }\end{array}$ \\
\hline 23 & Días de descanso/año & 17 & 17 \\
\hline 24 & $\begin{array}{l}\text { Número de horarios } \\
\text { posibles }\end{array}$ & $\begin{array}{l}3 \text { regulares. Abierto a } \\
\text { especiales y discontinuos }\end{array}$ & $\begin{array}{l}3 \text { regulares. Abierto a } \\
\text { especiales y discontinuos }\end{array}$ \\
\hline 25 & Grupos salarios & Dir.: 5/ind.: 9/aux.: 5 & Tec.: 11/esp.: 13/facs.: 4 \\
\hline 26 & $\begin{array}{l}\text { Primas de asistencia y } \\
\text { puntualidad }\end{array}$ & Mensual y anual & Mensual y anual \\
\hline 27 & Otras primas & $\begin{array}{c}\text { Trabajo en descanso } \\
\text { y vacacional }\end{array}$ & $\begin{array}{c}\text { Trabajo en descanso } \\
\text { y vacacional }\end{array}$ \\
\hline 28 & Aguinaldo & 50 días & 54 días \\
\hline 29 & Reparto de utilidades & $\begin{array}{l}26 \text { días de salario } \\
\text { como anticipo }\end{array}$ & $\begin{array}{l}28 \text { días de salario } \\
\text { como anticipo }\end{array}$ \\
\hline 30 & $\begin{array}{l}\text { Pago de cuotas al IMSS } \\
\text { e ISPT obreros }\end{array}$ & Cada trabajador & Cada trabajador \\
\hline 31 & Comedor & Sí & Sí \\
\hline 32 & Transporte & Sí & Sí \\
\hline 33 & Fondo de ahorro & No contempla & No contempla \\
\hline 34 & Despensa & Cantidad/Mens. & Cantidad/Mens. \\
\hline 35 & Retiro voluntario & $\begin{array}{l}60 \text { anuales después de } 17 \text { años, } \\
3 \text { meses y } 20 \text { días/año }\end{array}$ & $\begin{array}{c}60 \text { anuales después de } \\
17 \text { años, } 3 \text { meses y } \\
20 \text { días/año }\end{array}$ \\
\hline 36 & Jubilación & No contempla & No contempla \\
\hline 37 & Pago por conocimientos & No contempla & Sí \\
\hline 38 & Ayudas diversas & 5 clases & 5 clases \\
\hline 39 & $\begin{array}{l}\text { Permisos para el Comité } \\
\text { Ejecutivo y las comisiones } \\
\text { centrales }\end{array}$ & $\begin{array}{l}11 \text { permanentes, más } \\
8 \text { parciales }\end{array}$ & $\begin{array}{l}15 \text { permanentes, más } \\
8 \text { parciales }\end{array}$ \\
\hline 40 & $\begin{array}{l}\text { Permisos para comisiones } \\
\text { revisoras de CCT }\end{array}$ & 150 personas/dos semanas & 15 personas/dos semanas \\
\hline 41 & $\begin{array}{l}\text { Permisos para comisiones } \\
\text { revisoras de salarios }\end{array}$ & 30 personas/5 días & 5 personas/5 días \\
\hline
\end{tabular}




\begin{tabular}{|c|c|c|c|}
\hline 42 & $\begin{array}{c}\text { Permisos para delegados } \\
\text { seccionales }\end{array}$ & $282 / 1 \mathrm{hr}$. diaria & 11 permanentes \\
\hline 43 & $\begin{array}{c}\text { Permisos para delegados } \\
\text { departamentales }\end{array}$ & No contempla & $28 / 2$ hrs. día \\
\hline 44 & $\begin{array}{c}\text { Permisos para miembros } \\
\text { de comisiones mixtas }\end{array}$ & 28 & 26 \\
\hline 45 & Otro permisos & 3 parciales & No contempla \\
\hline 46 & $\begin{array}{c}\text { Ayuda para unidad } \\
\text { social y deportes }\end{array}$ & $\begin{array}{c}\text { Cantidad mensual por traba- } \\
\text { jador }\end{array}$ & No contempla \\
\hline 47 & $\begin{array}{c}\text { Ayuda para funciones } \\
\text { del CE }\end{array}$ & Sí. Cantidad mensual \\
\hline 48 & $\begin{array}{c}\text { Ayuda para fomento } \\
\text { del deporte }\end{array}$ & $\begin{array}{c}\text { Ayuda para } \\
\text { promoción cultural }\end{array}$ & Sí. Cantidad mensual mensual \\
\hline 50 & $\begin{array}{c}\text { Ayuda para caja } \\
\text { de ahorros }\end{array}$ & Sí. Cantidad mensual & Sí. Cantidad mensual \\
\hline 51 & Ayuda para Edif. Sind. & No contempla & No contempla mensual \\
\hline
\end{tabular}

Fuente: Herrera 1993:139-48

Si se clasifican las características o cambios producidos en el Contrato Colectivo de Trabajadoresde 1992, se deberían considerar al menos tres grupos: uno que contabilice las cláusulas a favor de la empresa, otro que haga lo mismo a favor del sindicato, y un tercero en donde se señalen las cláusulas que no presentaron variación alguna.

\section{Cuadro $\mathrm{N}^{\circ} 7$}

Clasificación en grupos de cláusulas del Contrato Colectivo de Trabajadores de 1992

\begin{tabular}{|c|c|l|c|}
\hline Clasificación & $\begin{array}{c}\text { A favor de la } \\
\text { empresa }\end{array}$ & A favor del sindicato & No presentan variación \\
\hline Cláusulas & $\begin{array}{c}1-2-3-5-6-7-8-9- \\
10-15-18-21-25-37- \\
40-41-42-44-46\end{array}$ & $22-28-29-39-43-45$ & $\begin{array}{c}4-11-12-13-14-16-17-20-23- \\
24-27-30-31-32-33-34-35- \\
36-38-47-48-49-51-51\end{array}$ \\
\hline Características & $\begin{array}{c}\text { Producción, } \\
\text { control, } \\
\text { disciplinamiento }\end{array}$ & $\begin{array}{c}\text { Aguinaldo, permisos, } \\
\text { reparto de utilidades }\end{array}$ & $\begin{array}{c}\text { Ayudas para actividades varias } \\
\text { del sindicato, jubilación, etc. }\end{array}$ \\
\hline
\end{tabular}

Fuente: Elaboración propia 
El cuadro expone, a grandes rasgos, tres tipos de cláusulas que podríamos catalogar de acuerdo a sus respectivas características como blandas, duras y constantes. Las blandas se caracterizarían por presentar cambios, que en lo concreto no representan un vuelco radical de lo que fuera anteriormente, es una leve variación. Las duras, por su lado, serían aquellas que sí representan cambios profundos respecto a su antecesora. Y, por último, las constantes serían aquellas que permanecen invariables en el tiempo o que señalan cierta conformidad en ambos grupos.

Así, entonces, las cláusulas que benefician al sindicato estarían dentro de las catalogadas como blandas, pues no implicaron cambios organizativos radicales en desmedro de la empresa ni tampoco grandes beneficios para el sindicato sino, por el contrario, comprenden resquicios como días de permisos para delegados, más días de aguinaldo, entre otras. El beneficio es, de esta manera, a corto plazo o de mediana envergadura.

Por el lado de las cláusulas denominadas duras se encontró que en su grueso, primero, hacen referencia hacia el control, disciplinamiento y, sobre todo, participación dentro de la empresa de los trabajadores(as) tanto a nivel sindical como en la misma organización del modelo productivo. Estas cláusulas, como tales, pasaron a beneficiar prácticamente en un ciento por ciento a VWM desde todo punto de vista, pues concierne la flexibilización del trabajo ya no como idea, sino como práctica diaria e idea de gestión.

Por último, se percibe que hay una gran variedad de cláusulas que no presentan cambio alguno y que en algunos casos benefician al sindicato (ayudas para el fomento deportivo), como otras que benefician a la empresa (no concebir jubilaciones). Las cláusulas que no variaron en los cambios producidos en 1992 pertenecen al grupo más numeroso con 25 cláusulas, representando aproximadamente el 50 por ciento de ellas.

Herrera (1993) señala que no es casual que en ninguno de ambos Contratos Colectivos de Trabajadores se haga referencia a alguna temática netamente productiva, como por ejemplo, la inclusión tecnológica. Ello es, sin duda, un área problemática que se repite en otras empresas en México y en la región sudamericana que podría tener, quizás, dos posibles explicaciones: primero, por una pasividad o escaso interés de parte del sindicalismo regional para con los mismos procesos productivos, abocándose siempre a mejorar condiciones urgentes (salario, aguinaldos, vacaciones, etc.), o, segundo, la empresa toma ciertas decisiones respecto a este punto a puertas cerradas, posiblemente, desde sus casas matrices, no dando con ello la posibilidad de discusión con el sindicato o, incluso, a la misma sucursal. En cualquiera de ambos casos, incluso plausibles en simultaneidad, el hecho denota un punto problemático en el mundo sindical y organizacional latinoamericano. 
Cabe destacar que se visibiliza dentro del caso de VWM una situación particular de más de 1.000 trabajadores que serían los llamados "eventuales" que, por lo general, son ocupados en distintas áreas del ensamblaje. Para el período 2010 fueron despedidos la totalidad de ellos, tras los ajustes productivos que hiciera la empresa por la baja demanda de vehículos y autopartes desde Estados Unidos. Estos trabajadores eventuales, si bien perciben algunos beneficios resueltos en la Ley Federal del Trabajo de México como utilidades y finiquitos tras término de contratos, su situación fluctúa en una permanente incertidumbre, pues incluso después de años de trabajo eventual, su despido puede hacerse sin consulta ni al sindicato ni al trabajador en particular. Ello sin obligatoriedad de reincorporación posterior, tal cual lo exhibe el artículo 49 de la misma ley. Es, en resumen, un trabajador formal pero informal a la vez. La flexibilidad en este caso asiente una relación contractual que depende directamente de la coyuntura del mercado internacional en su contratación y/o despido.

En resumen, la flexibilidad visible en el Contrato Colectivo de Trabajadores de 1992 posibilita un abanico amplio de acción a la empresa y disminuye lo propio a los trabajadores. La negociación colectiva, así, se reduce a la posibilidad de amortiguar de mejor manera la decisión ya tomada por VWM o, en su defecto, por VW Alemania. En este sentido, la precarización del trabajo formal toma forma como proceso ascendente y alerta de una difuminación con su contraparte al trabajo informal; incluyendo ambas formas en un nuevo tipo de trabajo. Por lo que el caso de VWM toma relevancia, pues en él se evidencia la paradoja del desarrollo industrial y la precariedad laboral.

\section{CONCLUSIONES: IDEAS FINALES EN TORNO A LA FLEXIBILIDAD LABORAL EN VWV}

"La vía impositiva para mejorar la productividad", así denominó Montiel (1993, 1992) al proceso flexibilizador en VWM. Esta vía tiene como eje central las alianzas estratégicas entre empresas multinacionales que ven, en América Latina, ventajas competitivas que no son sino la posibilidad de aumentar la productividad a través de un intenso proceso de flexibilización del trabajo formal. Lo que quiere decir, en otros términos, que es la mano de obra barata y la posibilidad de utilizarla de distintas formas, a través de este mecanismo, lo que hace atractiva la Inversión Extranjera Directa en este rubro y espacio específico.

Bajo los designios de la competitividad, VWM ejemplifica el proceso de cambio que envuelve al trabajo formal en la región y, sobre todo, a la forma organizacional que este adquiere en encadenamientos productivos como el acá bosquejado. Las formas de 
pensamiento que allí se recrean señalan un camino que Pries (2000) adelanta al establecer que la competitividad entiende que son factores blandos como la organización laboral, gobernabilidad, la que posiciona a una empresa en el mercado mundial. Gobernabilidad entendida como control, vigilancia y castigos que se adecuan a contextos específicos. Con ello, el fin parece ser válido bajo cualquier camino, pues hoy VWM se encuentra posicionada entre las automotrices más competitivas en el mercado automotor mundial.

No obstante, la paradoja surge cuando VWM se posiciona en el mercado mundial, pues mientras más se asienta el hecho, el trabajo en las autopartes mexicanas se vuelve más competitivo y más flexible; con ello, más precaria son las condiciones que caracterizan a este tipo de empleo. Por esta razón los conflictos que se suceden en VWM con su sindicato no son aislados, aunque en lo inmediato así se manifieste. Son, por el contrario, claro ejemplo de la voluntad empresarial de abaratamiento de costos humanos mas no productivos, y de la impotencia sindical de revertir esta situación (por ejemplo, en el traslado de VWM a Guanajuato), pues las decisiones provenientes desde VW Alemania encuentran eco en gobiernos locales dispuestos a atraer Inversión Extranjera Directa a costa de ofrecer plazas con bajos salarios y alianzas que restrinjan el actuar de los propios sindicatos.

La solución a esta problemática, como se aprecia, no estará presente en la negociación colectiva bajo los términos ya enunciados, pues esta se presenta infértil cuando es reacción o acatamiento. La discusión por nuevos Contratos Colectivos de Trabajadores será vital a la hora de crear encadenamientos productivos bajo cooperación, pero el desafío se presenta aún mayor cuando se asuma la incorporación de más actores sociales a la discusión. Tanto el sindicalismo (de VWM y toda América Latina y de los distintos proveedores) como los movimientos sociales locales y foráneos tienen alta responsabilidad en encontrar caminos que, lejos de acuerdos cerrados entre gobierno y empresa, busquen solución y presionen ante nuevas formas de explotación laboral en formato de reestructuraciones o flexibilidad (un ejemplo de ello son los intentos de crear alianza entre el sindicato de VWM y VW-Alemania). En este sentido, será preciso anticiparse a constituir acciones que resguarden al trabajador antes que la propia producción, pues en él recae la forma que lo constituye como tal y de él depende la propia producción. Si es la organización laboral la que posiciona a una empresa en el mercado mundial, será la misma entonces la que deberá hacer valer su importancia en los sistemas productivos como motor de cambio y no como su simple apéndice. 


\section{REFERENCIAS}

Álvarez, María. 2002. “Cambios en la industria automotriz frente a la globalización: el sector de autopartes de México." Contaduría y Administración 206:29-49. Consultado 3 de octubre de 2010 (http://www.bvsde.paho.org/bvsacd/cd51/automotriz.pdf)

Brown, Flor. 1997. La industria de autopartes mexicana: reestructuración reciente y perspectivas. México: Centro Internacional de Investigación para el Desarrollo, Universidad Autónoma de México. Consultado 15 de septiembre de 2010 (http://www.eclac.org/ddpeudit/proy/ clusters/autmex.pdf)

Carrillo, Jorge. 1997. "Maquiladoras automotrices en México: cluster y competencias de alto nivel." Pp. 194-234 en Competitividad, redes productivas y competencias laborales: ¿homogeneidad o segmentación?, coordinado por M. Novick y M.Gallart. Montevideo: OIT-CINTERFORD-Red Educación y Trabajo.

Carrillo, Jorge y Redi Gomis. 2003. "Los retos de las maquiladoras ante la pérdida de competitividad." Comercio Exterior 53 (4):318-27.

Coriat, Benjamin. 1995. "Les métamosphoses de la division du travail dans la crise contemporaine." Pp. 51-69 en La crise du travail, editado por J. Bidet y J. Texier. Paris: Presses Universitaires de France.

Cross, Barry y John Gordon. 1995. "Partnership strategies of market success.” Business Quartely 60 (1):91-6.

Dombois, Rainer. 1990. "Economía política y relaciones industriales en la industria automotriz mexicana." Pp. 35-63 en La nueva era de la industria automotriz en México, coordinado por J. Carrillo. México: El Colegio de la Frontera Norte.

García, Alejandro. 2008. “Trayectorias de coordinación entre Volkswagen y sus proveedores: las plantas de Brasil, Argentina y México.” Análisis Económico XXIII (53):173-200.

García, Alejandro y Arturo Lara. 2006. Cúmulos industriales y modularización productiva. Los vínculos de colaboración entre Volkswagen-Puebla y sus proveedores. Consultado 5 de octubre de 2010 (http://dcsh.xoc.uam.mx/produccioneconomica/publicaciones/MEMORIAS/2006/cumulos.pdf)

García, Alejandro y Eunice Taboada. 2007. "Formas de coordinación inter e intraempresa en la industria de los asientos automotrices: el caso de la planta de Lear Corporation en México.” Pp. 139-58 en Sistemas productivos locales en México, editado por X. Paunero y L. Corona. Gerona: Documenta Universitaria. 
Helper, Susan. 1991. "Strategy and Irreversibility in Supplier Relations: the case of the U.S. Automobile Industry." Business History Review 65:781-824.

Herrera, Fernando. 1993. "La flexibilización contractual en la industria automotriz de México." Polis. Investigación y análisis sociopolitico y psicosocial 93:131-54. Consultado 17 de octubre de 2010 (http://www.juridicas.unam.mx/publica/librev/rev/polis/cont/1993/pr/pr8.pdf)

Humphrey, John.1990. “The japanese model of industrial organisations: Can it be implanted in developing countries?” Ponencia presentada en el XII Congreso Internacional de Sociología, Madrid.

Humphrey, John y Hubert Schmitz. 1995. Principles for promoting clusters \& networks of SMEs. Brighton: University of Sussex.

Juárez, Huberto. 1999. “Nuevos sistemas de integración industrial y su impacto en las áreas de localización.” Ponencia presentada en el V Seminario Internacional de la RII, Toluca. Consultado 12 de diciembre de 2010 (http://www.cipi.gob.mx/Biblioteca_Digital_CIPI/bibliografiabasica/Encadenamiento por ciento20prodydereg/Ind-aut-VWPUEBLA.pdf)

-----. 2002. "Los sistemas just-in-time/Kanban, un paradigma productivo." Política y Cultura $18: 40-60$.

-----. 2010. "El SITIAVW pierde fuerza con decisión de la VW." Milenio.com. Consultado 22 de noviembre (http://impreso.milenio.com/node/8835845)

Katz, Jorge. 1989. "Reestructuración industrial y teoría del crecimiento económico." Pp. 1728 en Industria, Estado y sociedad:a reestructuración industrial en América Latina y Europa, editado por B. Belzunegui. Caracas: Eural-Fundación Friedrich Ebert.

Lara, Arturo, Alejandro García y Gerardo Trujano. 2003. ¿Existe un cluster automotriz-plástico en la región Toluca-Lerma? México D.F.: Universidad Autónoma Metropolitana-Xochimilco (mimeografiado).

Martínez, Aleida. 2008. "Subcontratación y calidad de los empleos: Volkswagen de México y su cadena productiva." Tesis para optar al grado de Magister en Gobierno y Asuntos Públicos, FLACSO, México. Consultado 2l de abril de 2010 (http://conocimientoabierto.flacso.edu.mx/ medios/tesis/martinez_a.pdf)

Montiel, Yolanda. 2007. Breve historia del Sindicato Independiente de Volkswagen de México. México: Friedrich Ebert Stiftung. Consultado 15 de agosto de 2010 (http://library.fes.de/pdffiles/bueros/mexiko/05370.pdf) 
2002. "Jornada reducida o despido. La participación democrática de los trabajadores en las decisiones de Volkswagen en Puebla." Ponencia presentada en el Dixième Rencontre Internationale du Gerpisa, 6-8 de junio, París.

Moreno, Juan Carlos. 1994. "La competitividad de la industria automotriz." Pp. 313-93 en La industria mexicana en el mercado mundial, editado por F. Clavijo y J. I. Casar. México: Fondo de Cultura Económica.

Mortimore, Michael y Faustino Barron. 2005. "Informe sobre la industria automotriz mexicana." Serie Desarrollo Productivo, CEPAL 169. Consultado 30 de agosto de 2010 (http://www. eclac.org/publicaciones/xml/1/22811/lcl2304e.pdf)

Novick, Marta. 2003. "La transformación de la organización del trabajo." Pp. 123-44 en Tratado latinoamericano de Sociología del Trabajo, editado por E. De la Garza. México: Fondo de Cultura Económica.

Novick, Marta y María Gallart, comps. 1997. Competitividad, redes productivas y competencias laborales. Montevideo: Cintefor.

Pries, Ludger. 1998. "Hacia un nuevo escenario de las relaciones industriales en la industria automotriz mexicana." Región y Sociedad IX (15):65-109.

-----. 2000. "Reestructuración productiva y estrategias de aprovisionamiento: el caso de Volkswagen de México en la región de Puebla." Región y Sociedad XII (19):161-79.

Ramírez, José. 1995. "The new location and interaction pattners. The mexican motor industry." Brighton: University of Sussex.

Roldán, Martha. 1993. "Industrial restructuring deregulation and new JIT labour processes in Argentina: Towards a gender-aware perspective?” IDS Bulletin 24 (2):42-52.

Salerno, Mario. 1992. "Modele japonais, travail brésilien." Pp. 305-28 en Modele japonais. Automatisation, nouvelles forms d'organisation et de relations de travail, editado por $\mathrm{H}$. Hirata. Paris: L'Harmattan.

SECOFI. 1994. "Principales proyectos de inversión extranjera." Comercio Exterior 44 (5):S/N.

Sosa, Sergio. 2005. "La industria automotriz de México: de la sustitución de importaciones a la promoción de exportaciones." Análisis Económico 44 (XX):191-213. 
Sturgeon, Timothy y Richard Florida. 1997. "The Globalization of the Automobile Production.” Ponencia presentada en el International Motor Vehicle Program Policy. 23-26 de septiembre, Kyung-Ju, Corea del Sur.

Vicencio, Arturo. 2007. "La Industria Automotriz en México: antecedentes, situación actual y perspectivas.” Contaduría y Administración 221:211-48.

Vieyra, José. 1999. El sector automotriz en el proceso de industrialización en México: aspectos histórico-económicos de su conformación territorial. México: Universidad Autónoma de México. Consultado 17 de octubre de 2010 (http://www.unizar.es/eueez/cahe/vieyra.pdf)

Villarroel, Diana y Marcela Villegas. 2007. Cambios en la localización de la industria automotriz en México 1994-2004. Serie Producción Económica. México: Universidad de Xochilimco. 